Different reaction paths, involving enzymes, might easily yield similar products without the intervention of radicals. It is here that the quantitative approach might help.

In general, the positions in which a further substituent is introduced into an already substituted benzene ring and the relative proportions of the possible isomers formed depend on the existing substituent or substituents and the nature of the substituting agent. There is no general agreement as to whether free-radical substituting agents should be subject to a directive action. If the directive action does not operate, all possible isomers should be formed in the statistically appropriate ratio ; that is, in the case of a monosubstituted benzene derivative, further substitution should yield one para-isomer for every two ortho and two meta formed, independently of the nature of the existing substituent. It has also been suggested ${ }^{14}$ that in free-radical substitution the quinonoid structure of the transition state is of such importance that substitution will always be preponderantly para with some ortho. It is agreed, however, that freeradical substitution should be quantitatively different from substitution by ionic agents, and thus a quantitative investigation of the substitution ratios by reagents known to yield free hydroxyl radicals is therefore of considerable interest.

The hydrogen-peroxide/ferrous salt reagent is not very well suited for quantitative investigations of this nature. However, we have used this reagent as the basis of a quantitative comparison with the action of ionizing radiations, and using nitrobenzene as the substrate we have shown that, within experimental error, the ratios of the three isomeric nitrophenols formed in either of these processes are practically identical ${ }^{\theta c}, 7 b$. In this case, where the existing substituent is the meta-directing $\mathrm{NO}_{2}$-group, all three possible isomers are formed in approximately equal quantities, the formation of the para-isomer thus being favoured.

We have now used the method of producing hydroxyl radicals by $\mathrm{X}$-rays (which is particularly suited for quantitative work) to investigate the ratio of isomers in the substitution of benzoic acid and phenol. Benzoic acid gave all three isomers in the ratio $p: 0: m$ approximately $10: 5: 2^{7 a, 7 d}$, whereas in the case of phenol no meta-isomer was found, the ratio $p: o$ being approximately $2: 1$ in neutral solution, and rising to approximately $8: 1$ in acid or alkaline solutions ${ }^{7 c}$. We have also investigated in some detail the effect of $p \mathbf{H}$ on the substitution ratios. All these results show that para substitution is generally favoured and that the ratio of the isomers depends on the primary substituent in a manner which is quantitatively different from other types of substitution.

To compare these results with experiments in vivo, reference can be made to the recent work of $R$. $T$. Williams et al. ${ }^{13}$ on the metabolism of aromatic compounds. Some of their results and those of Lederer et al. ${ }^{10}$ are not incompatible with the assumption of a free-radical mechanism in vivo, but more experimental results are needed before any definite conclusions can be drawn.

Even in those cases where there is quantitative agreement in the substitution ratios, it is by no means proved that hydroxyl radicals are actually operative in vivo. However, it would necessitate the assumption of transition states, which are effectively free radical in nature, though they may be formed on the surface of an enzyme, in the adsorbed state. There is also the possibility that more than one type of mechanism may operate at various biological sites, and while dihydro-diol formation ${ }^{17}$ may be the mode of action in one mechanism, at other sites free-radical substitution may operate. Preferential conjugation, rather than hydroxylation of intermediates, must also be considered before further conclusions can be drawn in this important problem.

1 (a) Bonhoeffer and Reichardt, $Z$. phys. Chem. 139, 75 (1928) (b) O'denberg and Rieke, J. Chem. Phys., 8, 169 (1938).

'(a) Haber and Willstătter, Ber., 64, 2844 (1931). (b) Franck and Haber, Suzb. Preus8. Akad. Wis8., 250 (1931).

* Haber and Weiss, Proc. Roy. Soc., A, 147, 332 (1934).

- (a) Baxendale, Evans and Park, Trans. F'arad. Soc., 42, 155 (1946). (b) Evans and Uri, Sympos. Photochemistry of Dyestuffs, Soc 119. (d) Weiss, ibid., 135 .

s Dainton, Nature, 160, 268 (1947).

- (a) Cross, Bevan and Heiberg, Ber., 33, 2015 (1900). (b) SteIn and Weiss, Nature, 161, 650 (1948). (c) Loebl, Stein and Weiss, $J$ Chem. Soc., 2074 (1949). (d) Merz and Waters, ibull., 2474 (1949). ' (a) Stein and Weiss. J. Chem. Soc., 3245, 3254 (1949). (b) Loebl, Stein and Weiss, ibid. 27ut (1950). (c) Stein and Weiss (to be published). (d) Loebl, Stein and Weiss, J. Chem. Soc. (in the press). (e) Day and stein, Nature, 164, 67i (19t9).

- Weiss, Nature, 153. 748 (1944); 157, 584 (1946); Trans. Farad. Soc., 43, 314 (1947); Brit. J. Radiology, Supp. 1, 56 (1947).

- (a) Carter and Weiss, Proc, Roy. Soc, A, 174, 351 (1940). (b) Welss and Porret, Nalure, 139,1019 (1937).

10 Unpublished experiments of T. Rigg.

"(a) Walker and Weiss, Trans. Farad. Soc, 31, 1011 (1935). Hückel, FIAT Reports, Theoretical Organic Chemistry.

"Williams, "Detoxication Mechanisms" (1947).

13 For example, Dakin, J. Biol. Chem., 4, 235 (1908).

14 Wheland, J. Amer. Chem. Soc., 64, 900 (1942).

16 Smith and Williams, Biochem. J., 46, 243 (1950), and references given there.

10 Lederer, J. Chem. Soc., 2115 (1949).

1" Cook, J. Chem. Soc., 1210 (1950). ef. Boyland, Biochem. Soc. Sympos, No. $5,40(1950)$.

\section{CLASSIFICATION, TRANSMISSION AND DETECTION OF ODOURS}

$A$ SYMPOSIUM on olfaction provided the main A item of interest at a special general meeting of the Society of Cosmetic Chemists, held in the main hall of the Chelsea Polytechnic, Manresa Road, London, S.W.3, on the evening of October 20.

The subject was introduced by Dr. William McCartney, of the Iodine Educational Bureau. Speaking on "The Mysteries of Olfaction", Dr. McCartney referred at some length and in very interesting detail to the literary and historical background of the subject, which as a basis for study certainly dates back to the ancients' preoccupation with incense and was specifically discussed by Theophrastus in his essay on odours. Throughout the Middle Ages interest in olfaction was sustained and later assumed considerable importance in the writings of Montaigne and of Robert Boyle, who not only enunciated the celebrated law that bears his name and isolated methyl alcohol and acetone, but also apparently detected the odour of musk emanating from a decomposed heap of manure.

Passing in brief review Hippolyte Cloquet's "Osphrésiologie" (1815 and 1921), Dr. MeCartney referred successively to the works of Saveliev, Zwaardemaker, Henning, Heyninx, Parker, Rógismanset, Von Skramlik and others, and then to the more recent contributions to the subject made by Kenneth, Moncrieff, Sagarin, McCord, Witheridge, Le Magnen, Duncan and Cheesman. Reference was also made to specialized works dealing with the sense of smell in animals, culminating in recent years with the valuable paper published by Walter. Olfactory perception among primitive peoples, the blind, and 
specialists such as tea-tasters and wine-tasters, represented a further approach.

Reference was doubtless intended to the investigations of Duncan and Cheesman in the observation that "in the domain of psycho-physiology, an up-todate examination of the application of the WeberFechner law to the sense of smell seems desirable", in that the technique of the two workers mentioned is based on the type of statistical approach directly derived from that law, which may be briefly set down in the following terms: "sensation is proportional to the logarithm of the stimulus, it being necessary to increase the stimulus geometrically in order to increase the sensation arithmetically"1.

The difficulties confronting the would-be measurer of odour intensities and the scientific investigator of odour qualities were mentioned by Dr. McCartney, who made no attempt to belittle them but nevertheless stopped short of the somewhat complacent references of Parry and Sagarin to what the latter has termed "the inherent invalidity of all systems of odour classification".

Dr. McCartney considered that vibratory or wave theories of odour transmission have "overwhelming evidence against them". In regard to the various theories held by Beck and Miles, Cheesman and Duncen, Duranton, Guillot, Le Magnen, McCord and Witheridge, Moncrieff and others, he felt it impossible that "all these theories, which are to some extent mutually exclusive, can stand the test of time". "In any case," he concluded, "the modern theories and the experimental results on which they are based provide ample material for much fruitful discussion. No scientific subject involves mysteries more profound than those of olfaction. And certainly no subject is more fascinating and absorbing."

The next speaker, Dr. G. H. Cheesman, confined most of his remarks to a description of the type of work now being carried out on odour classification at the University of Reading. After referring to the more obvious difficulties of devising a reliably objective, quantitative approach to the inherently subjective field of olfaction, he went on to emphasize the comparatively straightforward character of 'threshold' measurements, which can not only be determined with the minimum subjective interference, but are also susceptible to the psychological technique of factor analysis ${ }^{2}$.

Dr. D. R. Duncan, a former collaborator in this work with Dr. Cheesman, and the co-inventor with him of an improvement on the conventional FairWells osmoscope, then described in some detail the main features of the 'odour fatigue' method whereby threshold values are determined. Dr. Duncan had previously read a paper entitled "The Perception and Measurement of Odour" before the British Esperanto Scientific Association ${ }^{3}$.

A somewhat radical departure from the domain of determining threshold values was represented by the views of the next speaker, Dr. R. R. Matalon, of the Department of Colloid Science, University of Cambridge. Dr. Matalon harked back to the work of Prof. Henri Devaux, which had been briefly referred to in the introductory talk by Dr. McCartney. Devaux's experiments showed the phenomenon of odour transmission in visible form, as a surface-active effect on a bath of mercury covered with talc, the talc-dusted surface showing characteristic disturbance when subjected to the proximity of rose petals and other odorants4. Dr. Matalon went on to connect this fundamental work with the probable action of odorants on the cells or 'receptors' of the olfactory nerve system. It seemed to him that further basic research on these lines is an essential prerequisite to the objective study of odours and any acceptable attempt at scientific classification.

The final statement submitted to the symposium was a written contribution by Dr. J. H. Kenneth, of Edinburgh, whose "Osmics: The Science of Smell" was published in its complete form in $\mathbf{1 9 2 4}$.

The discussion started off somewhat slowly, but soon assumed a more interesting character-olucidation being not unmixed with critical comment and the statement of controversial opinions. Some speakers supported, for example, the vibrational theory of odour transmission, while others appeared even to doubt the validity of what is perhaps rather ambiguously described as 'odour fatigue'. The general feeling seemed to be in favour, on one hand, of the continuance of such work as is currently being undertaken by the University of Reading and, on the other, of devising a new type of approach to the subject that would logically continue the line of experimentation first indicated by Deveux. Among those who joined in the discussion were Mr. Jack Pickthall, Mr. E. S. Maurer, Mr. D. W. A. Waite, Dr. A. W. Middleton, Mr. Frank Atkins, Mr. James Bather and the Society's chairman, Mr. F. V. Wells.

'See R. W. Moncrieff's "The Chemical Senses", pp. 53-55.

2 See Soap, Perfumery and Cosmetic8, 697 (July 1949).

- See Nature, March 11, p. 394. "See R. W. Moncrieff's "The Chemistry of Perfumery Materials"
p. 279.

\section{RHEOLOGY AND THE CONSTITUTION OF MATERIALS ANNUAL CONFERENCE OF THE BRITISH
SOCIETY OF RHEOLOGY}

THE annual conference of the British Society of Rheology was held at St. Patrick's Hall, University of Rearling, during September 28-30. The general title of the conference was "Rheology and the Constitution of Materials", and the papers on this subject stimulated discussions ranging over a very wide range of materials from metals to polymer solutions. At the annual general meeting of the Society, the change of name from the British Rheologists' Club to the British Society of Rheology was sanctioned, a change which reflects the important part which the Society is playing both as a link between men of science from different fields of work in Great Britain and as a prime mover in the formation of the International Union of Rheology. The officers for 1950-51 are : President, Dr. G. W. Scott Blair ; Honorary Secretary, Dr. E. W. J. Mardles; Honorary Treasurer, Dr. J. G. Oldroyd; Honorary Editor, Dr. V. W. G. Harrison.

The presidential address, given on September 28 by Dr. G. W. Scott Blair, was on "The Rheology of Uterine Cervical Secretions". Dr. Scott Blair outlined the work which he and his colleagues have done on the relation of the properties of these secretions to the time of œstrus and the course of pregnancy for cows, and also similar studies made in conjunction with Mr. A. F. Clift for women. An emptying and filling capillary micro-viscometer was designed for this work which enabled measurements to be made with only $0.06 \mathrm{ml}$. of secretion. The original instrument, while giving very satisfactory results, was very tedious to use, and a new instrument giving 